\title{
THE IMPACT OF FEED ROLLERS ON THE QUALITY OF TIMBER IN THE MANUFACTURING OF POSTS
}

\author{
Agris Zimelis ${ }^{1}$, Andis Lazdiṇš ${ }^{1}$, Andis Ābele ${ }^{2}$ \\ ${ }^{1}$ Latvian State Forest Research Institute 'Silava' \\ ${ }^{2}$ Latvia University of Agriculture \\ agris.zimelis@silava.lv
}

\begin{abstract}
The aim of the study was to determine the impact of the harvester cutting head feed roller type on the mechanical damages of processed roundwood timber in post manufacturing. The study presents the comparison of the gentle Moipu plate wheel rollers and conventional feed rollers having bigger spikes (hereinafter named - conventional feed rollers). The total amount of segments processed with the gentle Moipu plate wheel rollers was 2199, whereas the amount of segments processed using the conventional feed rollers was 5308. When processing roundwood with the gentle feed rollers, in the $1^{\text {st }}$ flow $8.2 \%$ of timber was rejected as substandard due to defects. The corresponding figure in the $2^{\text {nd }}$ flow was $5.2 \%$ of the material in which the damage in the form studs was caused by the feed rollers. When processing the timber with conventional feed rollers, the percentage of the damage - dents caused by these rollers in the $1^{\text {st }}$ flow was $26.7 \%$, in the $2^{\text {nd }}$ flow $-43.7 \%$ and in the $3^{\text {rd }}$ flow only $2.7 \%$. Using the method of characteristics proportion comparison, significant differences have been observed between feed rollers $\left(\mathrm{t}=17.8>\mathrm{t}_{0.05 ; \infty}=1.96\right)$.
\end{abstract}

Key words: feed roller, timber damages, harvester.

\section{Introduction}

The damages to roundwood timber caused by feed rollers were already observed when the first harvesters were used in 1970. The modern harvesting machine harvester - divides the stem into segments with a high precision and speed, but damages to wood caused by the feed rollers or delimbing knives are considered to be a side effect. The harvester head is fitted with a cutting mechanism and feed rollers, which can also carry out the the measuring operation. During the process of bucking and delimbing, the stem is pressed between the feed rollers when it is passed forward. As a result, damages in the form of dents occur in the bark and wood (Karaszewski et al., 2016; Nuutinen et al., 2010; Sowa, Gieralowiec, \& Gaj-Gieralowiec, 2013; Uusitalo et al., 2000).

Based on the data of 2006 obtained from the Finnish research institute, the annual allowable volume of felling by a harvester is $50.8 \mathrm{mil} \mathrm{m}^{3}$ which is $98 \%$ of the entire volume of the processed wood. In Latvia, it is possible to compare the previous year's parameters and average harvesting volume of $84 \%$ (final felling, commercial thinning, cutting of damaged trees). Harvesters are most intensively used in the final fellings $-97 \%$. Having such harvesting volumes it is important to choose the most suitable feed rollers, and to evaluate this parameter the following factors should be taken into consideration: work productivity, costs, efficiency and damages to roundwood.

The dents caused by feed rollers lead to blue stain in timber which is located in felling sites or the consumers' yards. Apart from the blue stain, the dents caused by the feed rollers also reduce the yield of the end product in the wood processing enterprises.

The studies on feed rollers and the possible solutions to the problems caused by them had been initiated since harvesters were introduced. Today the most popular on the market are the feed rollers made of metal. They have a higher throughput capacity, as a result of which the work productivity is higher compared to those feed rollers which are made of rubber (Nuutinen et al., 2010). In Scandinavia, the following types of feed rollers are widely studied: 'Ponsse taper-foot feed rollers', 'Mense', 'LogMax flexi-wheel', 'ponsse limited-pivot plates', 'John Deere V-type', 'Moipu' (Brunberg et al., 2007; Gerasimov, Seliverstov, \& Syunev 2012; Nuutinen et al., 2010).

The aim of the study was to determine the impact of the harvester cutting head feed roller type on the mechanical damages of processed roundwood timber in post manufacturing.

\section{Materials and Methods}

Experimental harvesting tests were carried out in Vidusdaugava forestry using Ponsse Ergo fitted with the harvester cutting head H7. Using the gentle feed rollers, 19 felling sites with a total area of 18.69 ha were harvested (the average area of the site was 0.98 ). Using conventional feed rollers, 15 felling sites with a total area of 20.29 ha were harvested ( the average area of the site was $1.35 \mathrm{ha}$ ); the distribution of species in the stands was similar. Logging was done from May 27, 2016 to June 30, 2017. Comparing harvester productivity figures to rainfall does not have a significant effect on technical productivity.

To carry out the research, spruce and pine roundwood timber was used, which had the entire sawn plane of the top part of the stem marked with paint. This type of marking is necessary to differentiate the timber processed with feed rollers of different construction types. 


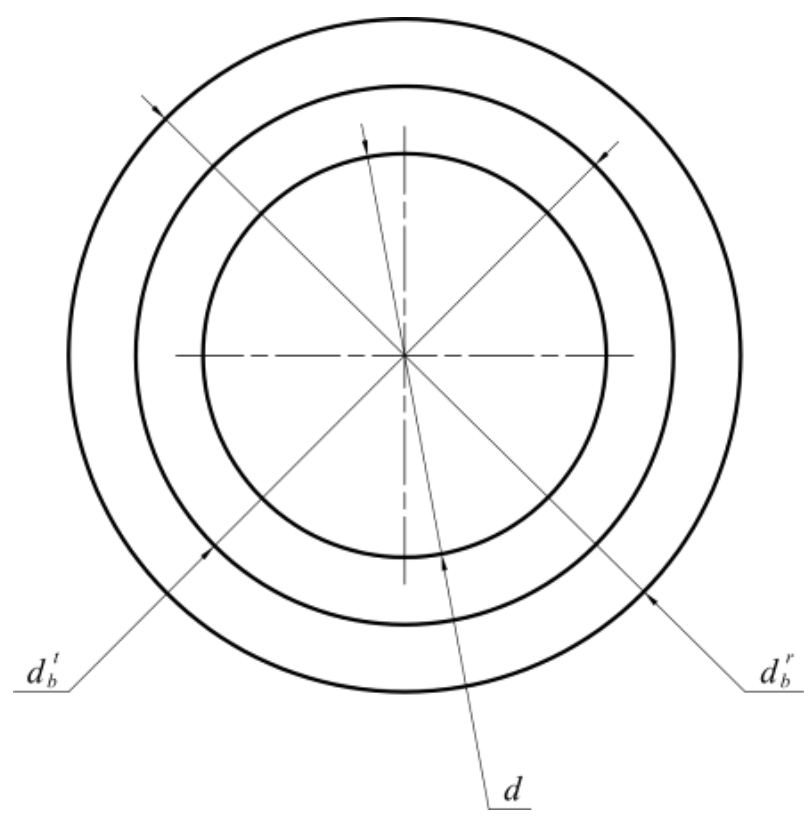

Figure 1. Roundwood timber milling scheme.

$\left(d_{b}^{t}\right.$ - roundwood timber top stem part diameter; - post diameter; $d_{b}^{r}$ - roundwood timber butt end diameter).

The total volume of roundwood timber processed with gentle and conventional feed rollers delivered to the enterprise for manufacturing posts was 138 $\mathrm{m}^{3}$. In total, delivered and processed with the gentle feed rollers were $28 \mathrm{~m}^{3}$ (2 199 segments) but with conventional feed rollers $-110 \mathrm{~m}^{3}$ (5 308 segments), which were divided into the processing diameter classes.

In the enterprise, the roundwood timber (Figure 1) with the average diameter of the top of the stem of $70,80,95$ and $120 \mathrm{~mm}$ is used for the manufacturing of posts, taking into account a $2 \mathrm{~cm}$ overmeasure in relation to the diameter of the end product. Consequently, all 4 diameter groups were checked within the framework of the study, but from the different lengths only those were selected in which a significant impact of the dents resulted in by the feed rollers on the quality of posts can be observed. Based on the information rendered by the enterprise, the most serious damages were observed on the posts manufactured from $3.3 \mathrm{~m}$ long roundwood timber. Thus, the roundwood timber of the appropriate diameter of the top part of the stem having the length of $3.4 \mathrm{~m}$ was prepared for the study, taking into account $0.1 \mathrm{~m}$ length of overmeasure.

The amount of the roundwood timber processed within the framework of the study was equalled to the amount the enterprise processes during one shift. Based on the information given by the enterprise, the average feed productivity of the roundwood timber processing technological flow is from 40 to $50 \mathrm{~m}^{3}$ roundwood timber in one shift. Consequently, within the framework of the study, the required total volume of all 4 roundwood diameter groups processed with one construction type harvesting machine's feed rollers was asumed to be $40 \mathrm{~m}^{3}$ which corresponds to the useful load of a roundwood vehicle with trailer. The processed roundwood which within the framework of the research was delivered to the enterprise by trucks, before further processing was piled in the sorting and storage yard in separate non-sorted stacks where they were sorted according to the diameter of the top part of the stem.

The roundwood, sorted according to the diameter of the top part of the stem, was forwarded to two post manufacturing technological flows located in buildings 11 and 16 (Figure 2) where identical post manufacturing technology was used. In building 11 the roundwood with stem top part diameter of 70 and $80 \mathrm{~mm}$ was processed, and in building 16 (Figure 2) the roundwood with the stem top part diameter of 95 and $120 \mathrm{~mm}$ was processed. When starting the manufacturing of posts in building 11 , the roundwood was conveyed to the separating and feeding equipment 3 , where it was separated in a |single mode and conveyed to the longitudinal conveyor 4 which in turn conveyed it through the turning milling machine 5 to the longitudinal conveyor 6 . From the longitudinal conveyor 6 the roundwood was conveyed to the transverse coveyor 7 and then further to the longitudinal conveyor 8 , which fed it into the second turning and milling machine 9 (Figure 2), thus obtaining the required post diameter. The milled post templates were 

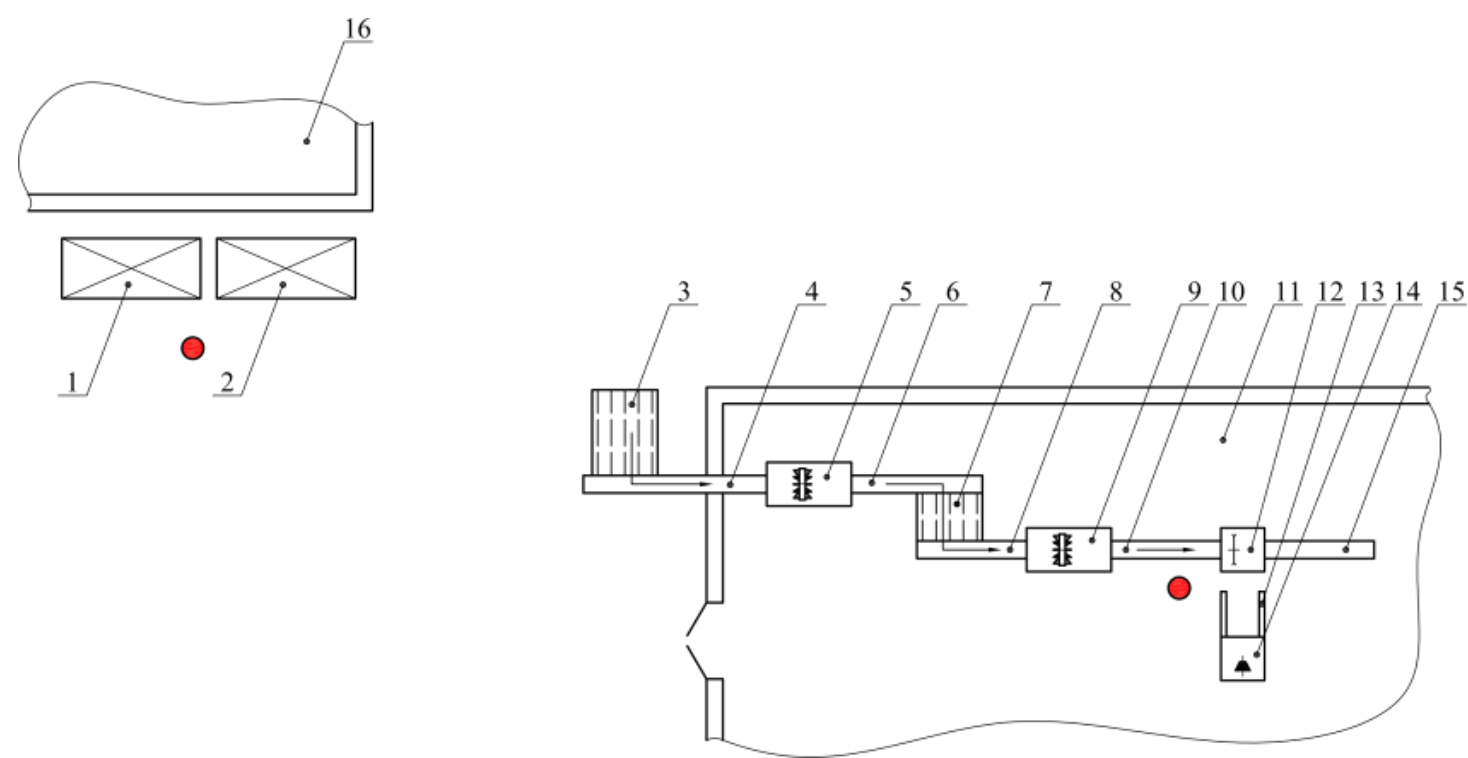

Figure 2. Technological scheme of the roundwood processing areas of an enterprise

(1,2 - rejected stacks of posts; 3 - roundwood timber separation and forwarding/conveying equipment; 4,6 , 8, 10, 15 - longitudinal conveyors; 5, 9-turning milling machines; 7 - transverse transporter; 11 - building of the 1 st technological flow; 12 - cross cutting circular saw; 13 - the scaffolding bridge for loading bucked posts; 14 - cone shaping milling machine; 16. - building of the 2 nd technological flow; $\bigcirc$ - evaluation positions of the impact of the dents made by the feed rollers of forest harvesting machines on the posts)

evaluated on the longitudinal conveyor 10 (Figure 2) to make sure that the respective template was suitable for further processing. If deep damages dents - were found on the post templates, these posts were discarded from the technological flow and delivered further for storage in stacks 1 and 2 (Figure 2). The suitable post templates were bucked with a crosscuting circular saw 12 according to the nominal length of the posts and these bucked segments of the posts were forwarded to the scaffold bridge 13 from where the end cone was carried out with a milling machine 14 (Figure 2).

The impact of the dents made by the feed rollers of forest harvesting machines on the posts was evaluated prior to the bucking operation in the storage places where the discarded post stacks were stored (in the positions marked with a symbol $\bigcirc$ (Figure 2 ). The evaluation was carried out by visual observation of all the template generatrix surfaces of posts determining whether the dents were observed on the generatrix surface. The result was expressed according to the number of post templates. Evaluating the dents caused by the feed rollers, the existing quality requirements of post delivery were not followed.

The amount of the damaged posts in proportion to the total amount of posts, which is possible to process from the delivered volume of roundwood, $\eta \%$ in the framework of each diameter group was calculated using the following formula:

$$
\eta=\frac{10^{2} \cdot \sum M_{b i}}{\sum M_{i}}
$$

where: $\sum M_{b i}-$ number of damaged posts of diameter group

$\sum Z_{i}-$ total possible number of posts of diameter group.

Economic aventages due to the use of gentle feed rollers were calculated by the enterpreneur on the basis of comparison of rejected logs, reduction of volume of logs and cost of repeated processing of poles. Production costs, as well as costs of the feedstock are considered as sensitive information by the enterpreneur and are not included in the article.

\section{Results and Discussion}

During the processing stage the recording was carried out in which the information was reflected on the amount of the processed and damaged products according to the types of the feed rollers (Table 1). Additionally, the recording of 'other causes' (other than feed rollers, such as bark and insect damages, etc.) concerning the damages to the product was carried out. In further calculations the roundwood damaged due to other causes was not separately distinguished. It was added to the total processed amount of product (Table ) 
Table 1

Total amount of roundwood used in production

\begin{tabular}{|l|c|c|c|}
\hline \multicolumn{1}{|c|}{ Type of feed rollers } & Flow & $\begin{array}{c}\text { Damages caused by feed } \\
\text { rollers, pieces }\end{array}$ & $\begin{array}{c}\text { Products manufactured, } \\
\text { pieces }\end{array}$ \\
\hline Gentle feed rollers & 1 & 181 & 2018 \\
\hline Gentle feed rollers & 2 & 9 & 165 \\
\hline Gentle feed rollers & 3 & - & 4 \\
\hline Conventional feed rollers & 1 & 1416 & 3892 \\
\hline Conventional feed rollers & 2 & 482 & 622 \\
\hline Conventional feed rollers & 3 & 16 & 571 \\
\hline Conventional feed rollers & 4 & 1 & 0 \\
\hline
\end{tabular}

When processing the roundwood with gentle feed rollers in the 1st flow (the flow indicates the number of repetitions of how many times the material is repeatedly milled until it meets the quality requirements of the consumer) $8.2 \%$ was rejected and in the 2 nd flow $5.2 \%$ of the material was rejected due to the dents damages caused by the feed rollers. Processing the material produced with the conventional feed rollers resulted in $26.7 \%$ of logs rejected as defective in the $1^{\text {st }}$ flow due to dents made by the feed rollers , $43.7 \%$ - in the $2^{\text {nd }}$ flow and $2.7 \%$ - in $3^{\text {rd }}$ flow. Consequently, $26.7 \%$ of the material had to be processed twice and $11.7 \%$ - three times and $0.3 \%$ was rejected completely at the end. A small number of rejected logs after the $3^{\text {rd }}$ processing actually means that the most of the dents are shallower than thickness of stem layer removed during the processing.

Repeated reduction of diameter of poles during processing considerably reduces their value and results in additional production costs. In order to find out the economic advantages due to use of gentle feed rollers, the losses for the milled material have been calculated repeatedly. With the increase in the diameter of roundwood "posts" dimension within the range of $85-100 \mathrm{~mm}$, the dents caused by harvester feed rollers increase significantly, irrespective of the type of the feed roller (Figure 3). The task of the feed rollers is to control and to move timber through delimbing knives, eliminating the possibility of their sliding out or getting serious dents (Leszczy, Przyrodniczy, \& Ogrodniczych, 2014). Analysing the amount of the rejected products, it was found that conventional feed rollers cause more significant losses since their impact can still be observed after the third milling phase (Figure 4). Using the method of characteristics proportion comparison, significant differences were observed between the feed rollers $\left(\mathrm{t}=17.8>\mathrm{t}_{0.05 ; \infty}=1.96\right)$.

Analysing the total delivered volume after processing (Table 2) with the gentle feed rollers, the expected yield of the product is $17.24 \mathrm{~m}^{3}$, whereas

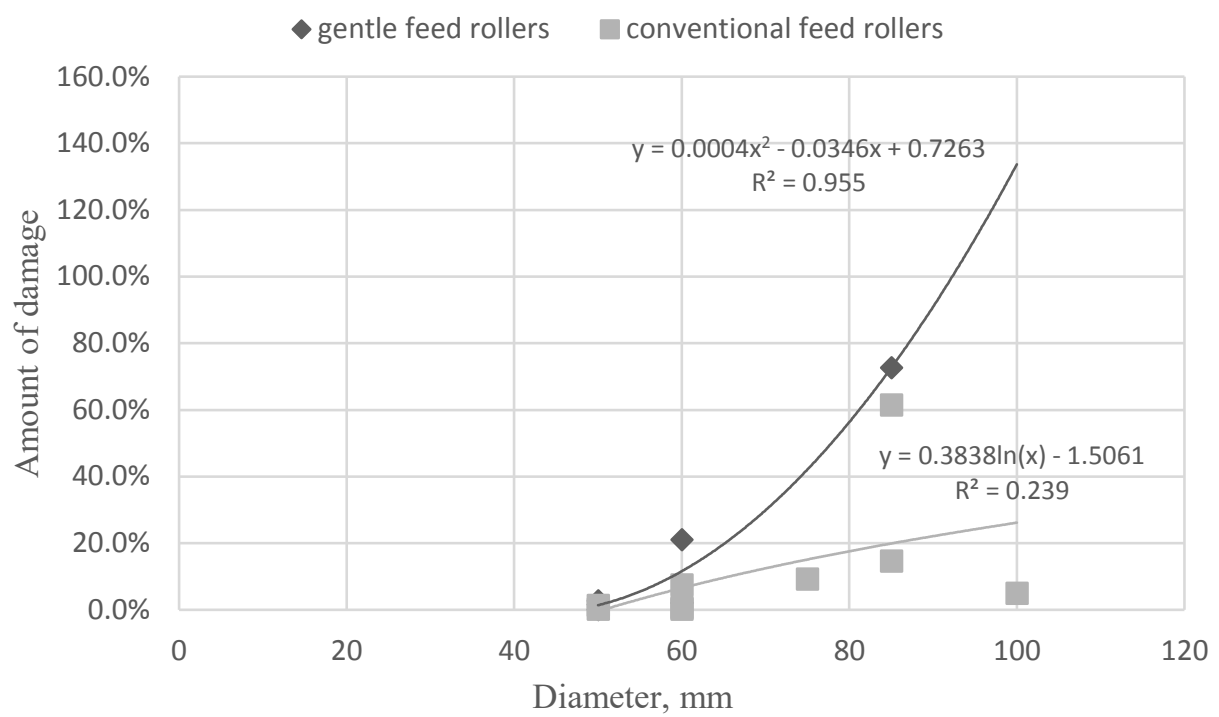

Figure 3. Changes of dents caused by feed rollers depending on diameter. 


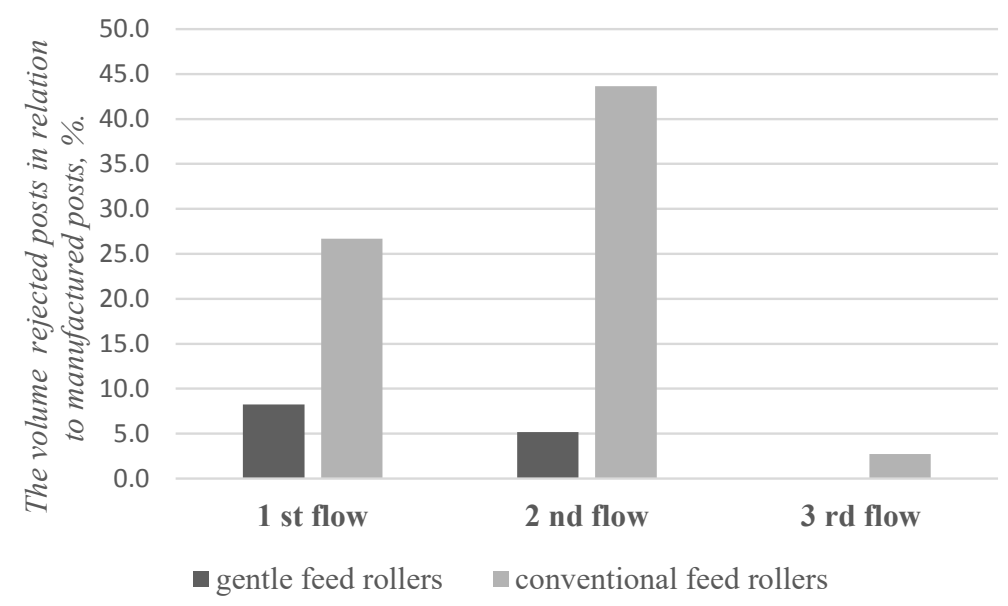

Figure 4. Breakdown of proportion of rejected materials by flows.

Total volume of roundwood used in production

\begin{tabular}{|c|c|c|c|}
\hline Type of rollers & Flow & $\begin{array}{c}\text { Damages caused by feed } \\
\text { rollers, } \mathrm{m}^{3}\end{array}$ & Products manufactured, $\mathrm{m}^{3}$ \\
\hline Gentle feed rollers & 1 & $1.84( \pm 0.86)$ & 15.40 \\
\hline Gentle feed rollers & 2 & 0.04 & 0.89 \\
\hline Gentle feed rollers & 3 & - & 0.02 \\
\hline Conventional feed rollers & 1 & $15.96( \pm 6.44)$ & 35.56 \\
\hline Conventional feed rollers & 2 & $4.93( \pm 1.51)$ & 5.90 \\
\hline Conventional feed rollers & 3 & 0.09 & 3.53 \\
\hline
\end{tabular}

using the conventional feed rollers it is expected to be as high as $52.25 \mathrm{~m}^{3}$.

When applying gentle feed rollers, the total lost volume of wood in the process of milling was 1.84 $( \pm 0.86) \mathrm{m}^{3}$, but when conventional feed rollers were used, the corresponding figure was $15.96( \pm 35.56) \mathrm{m}^{3}$. This amount was later used in the production of chips.

The loss was calculated based on the volume of roundwood timber of JSC 'Latvijas Valsts meži' delivered in 2015. Comparing the gentle feed rollers with the conventional ones, the loss in terms of money was 6.53 EUR per $\mathrm{m}^{3}$.

\section{Conclusions}

1. As a result of the study, a significant impact of gentle feed rollers on the proportion of the rejected material in the manufacturing process of posts was stated - in the harvesting process with gentle feed rollers the amount of rejected posts after the first milling cycle was $8.2 \%$, but for the material which was processed with conventional feed rollers, the amount of rejected posts was $26.7 \%$

2. The most significant damages were to the posts within the diameter range of $85-110 \mathrm{~mm}$.

3. Forest prepared amount of wood to the processing plant products are prepared by $59 \%$, which points to the need to modernize the overall production process.

\section{Acknowledgements}

The study was implemented within the scope of the JSC funded research project 'Research program on forest biofuel and mechanization of forest operations' (agreement No 5-5.9_003v_101_16_47).

\section{References}

1. Brunberg, T., Hofsten, H.V., Jonsson, M., \& Jönsson, P. (2007). Stud damage to logs — research and evaluation. Skogforsk, 1(1), 4.

2. Gerasimov, Y., Seliverstov, A., \& Syunev, V. (2012). Industrial Round-Wood Damage and Operational Efficiency Losses Associated with the Maintenance of a Single-Grip Harvester Head Model: A Case Study in Russia. Forests, 3, 864 - 880. DOI: 10.3390/f3040864. 
3. Karaszewski, Z., Łacka, A., Mederski, P.S., Noskowiak, A., \& Bembenek, M. (2016). Damage caused by harvester head feed rollers to Alder, pine and Spruce. Drewno, 59(197). DOI: 10.12841/wood.1644-3985. C36.08.

4. Leszczy, N., Przyrodniczy, S.K.I.U., \& Ogrodniczych, M. (2014). Rolki posuwu glowic harwesterowych (Feed rollers of wood harvesting heads). Technika Rolnicza Ogrodnicza Leśna, 6 - 8. Retrieved February 15, 2017, from: yadda.icm.edu.pl/yadda/element/bwmeta1.element.agro-068ae8d9-649d-4ef0-8de0a9d58ec980c1/c/WL3_2014.pdf. (in Poland).

5. Nuutinen, Y., Väätäinen, K., Asikainen, A., Prinz, R., \& Heinonen, J. (2010). Operational efficiency and damage to sawlogs by feed rollers of the harvester head. Silva Fennica, 44(1), 121 - 139. DOI: 10.14214/ sf. 165 .

6. Sowa, J., Gieralowiec, K., \& Gaj-Gieralowiec, D. (2013). Characteristics and development of the construction of logging harvester heads. Forestry Letters, 105(3).

7. Uusitalo, J., Eronen, J., Asikainen, A., \& Sikanen, L. (2000). Control of log end checks during bucking with a modified single-grip harvesters. Forest Products Journal, 50(5), 6. Retrieved January 25, 2017, from: http://eds.a.ebscohost.com/eds/pdfviewer/pdfviewer?sid=1bf663a0-ed79-4722-900d8435213a97ae\%40sessionmgr4010\&vid=1\&hid=4213. 